\title{
Legumes: Model Plants for Sustainable Agriculture in Calcareous Soils
}

\author{
Wissal M'sehli*, Kallala Nadia and Haythem Mhadhbi \\ Laboratory of Legumes, Centre of Biotechnology of Borj-Cedria, Hammam-Lif, Tunisia \\ *Corresponding author: Laboratory of Legumes, Centre of Biotechnology of Borj-Cedria, Hammam-Lif, Tunisia
}

\begin{abstract}
Nowadays, the agriculture's target is the reach of an amount of crop production that can cover the need to feed growing world population with the crucial challenge of respecting the environment. Several environmental constraints are limiting world agricultural production, mainly the preponderance of calcareous soils suffering from ferric and phosphoric deficiencies. In calcareous soils, legumes were considered as an alternative solution to retrieve a fertile soil without the abusive use of chemical fertilizers. The ability to establish a symbiotic associations with nitrogen-fixing soil bacteria is the way used by legumes to restore soil organic matter and to improve soil fertility. Legumes remain a source of healthy food while respecting the environment. This mini review describes the importance of legumes for Fe and P deficient soils management through sustainable practices.
\end{abstract}

\section{Introduction}

According to the United Nations estimation, the human population will be reaching 9.7 billion by mid-century and 11.2 billion by century's end [1]. Unfortunately, the same ascending slope was observed also for the world hunger. In this regard, the Food and Agriculture Organisation marks that hunger is increasing [2] which has a direct relationship with the depressed agricultural productivity in many countries especially the low-income ones. The agricultural productivity loss is attributing to many environmental factors including soil nutrient deficiencies [3]. In fact, this environmental problem is widespread in calcareous soils that cover more than $30 \%$ from the surface of the earth [4]. In those soils, plant growth is often restricted by soil physico-chemical conditions (high $\mathrm{pH}$ values and bicarbonate concentrations) which causes a decrease in mineral nutrients bioavailability principally iron (Fe) [5] and phosphorous (P) [6]. A common approach that is adopted to overcome Fe and P deficiencies of plants on calcareous soils and consequently improve human diet is the fertiliser applications. However, it was noted that the improper use of agro-chemicals causes environmental pollution and decreases the efficiency of nutrient use [7]. As an alternative to chemical fertilizers, legumes have a significant role in agriculture providing economic benefits and meeting human demand for protein particularly in developing countries. In this regard, it has been shown that legumes improves soil fertility, restores soil organic matter and reduces pest and disease problems when using during crop rotation [8]. In this review paper, we provided an overview of the importance of legumes in overcoming $\mathrm{P}$ and Fe deficiencies in calcareous soils.

\section{Legumes Tolerance to Soil P Deficiency}

Soil $\mathrm{P}$ deficiency is a crucial limitation for agricultural productivity in developing countries which has led to an important enhancement of chemical fertilizers applications. To ovoid the negative impact of those fertilizers on the environment, several researchers have proposed the inclusion of legumes in P-deficient soils as an alternative solution to the application of fertilizers. In this context, research findings have revealed the effectiveness of legumes in calcareous soils suffering from $P$ deficiency [9]. Accordingly, this efficiency contributes to the decrease in the use of fertilizers as well as the increase of soil fertility and health. Under P-limited conditions, legumes have evolved various adaptation mechanisms to tolerate $\mathrm{P}$ stress [10] that will contribute to a stimulation of the root's extracellular acquisition of rhizosphere soil $\mathrm{P}$ or the optimization of its intracellular use efficiency [11]. Morphological responses are summarized in the modification of the root architecture (root surface area, root length, cluster roots) which increased P uptake [12].

The most typical root responses of plants in increasing the solubilisation of soil $\mathrm{P}$ is the decrease in rhizosphere $\mathrm{pH}$ by the release of $\mathrm{H}+$ and phosphatases acids to the rhizosphere [12]. Enhancement of acid phosphatase activity (APases) under $\mathrm{P}$ 
starvation conditions has been demonstrated for N2- fixing legumes including Vicia faba [12], Lupinus albus and Glycine max [13, 14]. Studies in Vicia faba and Vicia sativa showed that $P$ deficient plants increased both extracellular APases, which are involved in hydrolysis of soil's various organic phosphate monoesters, and intracellular enzymes acting in the remobilization of Pi from rich $\mathrm{P}$ components inside the plant cell [12].

With P deficiency, the concentration of phenols increases to improve the availability of the sparingly soluble soil P for plants [15]. In Vicia faba, the exudation of phenolic compounds have been reported a higher concentrations in P-deficient plants [12]. Likewise, it has been demonstrated that Lupines albus and Brassica napus released large amounts of phenolics into the rhizosphere in response to $\mathrm{P}$ deficiency [16]. The maintenance of the P-homeostasis in nodules is considered as a main adaptive strategy for rhizobialegume symbiosis under $\mathrm{P}$ starvation by increasing $\mathrm{P}$ allocation to nodules, formation of a strong $\mathrm{P}$ sink in nodules and direct $\mathrm{P}$ acquisition and remobilization [15].

\section{Legumes Tolerance to Soil Fe Deficiency}

In the face of Fe deficiency widespread in calcareous soils, legumes have evolved adaptive strategies in order to tolerate the stress and increase $\mathrm{Fe}$ bioavailability [15]. The main adaptive responses are the rhizosphere acidification by the activation of plasma membrane H+-ATPase, the stimulation of the reduction of $\mathrm{Fe} 3$ + to $\mathrm{Fe} 2$ + by a NADPH-dependent Fe (III)-chelate reductase (FCR) and the stimulation of root exudates [17]. Several research have been described the genetic variability among legumes regarding their tolerance to $\mathrm{Fe}$ starvation. In fact, there are numerous studies aimed to identify and select legume species and genotypes tolerant to Fe deficiency with the potential to increase agriculture production in calcareous soils [18]. assessed the genetic variability among 12 cultivars of peanut (Arachis hypogaea L.) in tolerance to iron deficiency based on spectral and photosynthetic parameters. These authors selected three groups according to their tolerance to Fe deficiency:
a. a Fe-deficient tolerant cultivar ('Zhenghong 3'),
b. a Fe-deficient sensitive cultivar ('Huayu 22'), and
c. ten intermediate cultivars. In a complimentary study,

[19] have studied the tolerance of two lines of Medicago ciliaris (TN11.11 and TN8.7) to Fe deficiency and found that TN11.11 line has a potential to enhance revegetation in calcareous soils for pastoral use. In addition, a study was carried out by [20] in order to investigate the biodiversity within Medicago truncatula plants in response to Fe deficiency, to identify tolerant genotypes and to assess the main tolerance mechanisms. Based on biometric and physiological markers, those authors found a biodiversity among the 20 genotypes studied toward tolerance to iron deficiency. In the same way, [21] have been reported the higher Fe deficiency tolerance of Medicago ciliaris as compared to Medicago truncatula. Legumes are distinguished by their ability to establish symbiotic associations with nitrogen-fixing bacteria and with arbuscular mycorrhizal to facilate the acquisition of nutrients such as Fe. It has been demonstrated that symbiotic nitrogen fixation and ammonium assimilation induce soil acidification and therefore increase of Fe bioavailability [22] showed that the inoculation of Medicago truncatula genotypes with two Sinorhizobium strains ameliorates the tolerance of Fe-deficient plants to Fe starvation. Theses authors stated also that both Sinorhizobium strains (TII7 and SII4) stimulates the antioxidant enzyme activities in Fe-deficient plants. In addition, rhizobia can also produce strain specific siderophores that can help overcome iron starvation [15].

\section{Conclusion}

In arid and semiarid regions, alkalinity is an important environmental constraint for nutrients bioavailability especially $\mathrm{Fe}$ and P, which leads to lower crop production. Factors that contribute to $\mathrm{Fe}$ and $\mathrm{P}$ deficiencies in calcareous soils are high $\mathrm{pH}$ values and bicarbonate concentrations. Improving crop production in such soils demand adoption of special management practices which aims to ensure sustainable agriculture that respects the environment. The introduction of legumes in calcareous soils sustain productive agriculture. Hence, it is primordial to select rhizobia strains and legumes genotypes with enhanced tolerance able to thrive under nutrient limiting conditions and subsequently the use of these selected genotypes in crop rotation.

\section{References}

1. United Nations (2015) World populations prospects, the 2015 revision.

2. World health Organization (2019) World hunger is still not going down after three years and obesity is still grown-UN reports.

3. Reynolds TW, Waddington SR, Anderson CL, Chew A, True Z, et al. (2015) Environmental impacts and constraints associated with the production of major food crops in Sub-Saharan Africa and South Asia. Food Sec 7: 795-822.

4. Taalab AS, Ageeb GW, Siam HS, Mahmoud A (2019) Some characteristics of Calcareous soils. A review. Middle East Journal of Agriculture Research 8(1): 96-105.

5. Briat JF, Dubos C, Gaymard F (2015) Iron nutrition, biomass production and plant production quality. Trends in Plant Science 20(1): 33-40.

6. Houssin D, Latati M, Rebouh NY, Gérard F (2019) Phosphorus acquisition processes in the field: study of faba bean cultivated on calcareous soils in Algeria. Archives of Agronomy and Soil Science 66(2).

7. Davydov R, Sokolov M, Hogland W, Glinushkin A, Markaryan A (2018) The application of pesticides and mineral fertilizers in agriculture. MATEC web of conferences.

8. Das A, Ghosh PK (2012) Role of legumes in sustainable agriculture and food security: An indian perspective. Outlook in agriculture 41(4): 279284.

9. Mitran T, Meena RS, La R, Layek J, Kumar S, Datta R (2018) Role of soil phosphorus on legume production. In book: Legumes for Soil Health and Sustainable Management, Publisher: Springer, Editors: Ram Swaroop Meena, Anup Das, G.S. Yadav, Rattan Lal.

10. Sulieman S, Phan LS (2015) Phosphorus homeostasis in legume nodule as an adaptive strategy to phosphorus deficiency. Plant Science 239: 3643.

11. Vance CP, Uhde-Stone C, Allan DL (2003) Phosphorus acquisition and use: Critical adaptations by plants for securing a non-renewable resource. New phytol 157(3): 423-447.

12. M'sehli W, Jaleli K, Kallala N, Mhadhbi H (2018) Relationship between phosphorus deficiency tolerance and root/rhizosphere management in Vicia faba and Vicia sativa. Journal of Animal \& Plant Sciences 37(2): 6019-6032. 
13. Hinsinger P, Betencourt E, Bernard L, Brauman A, Plassard C, et al. (2011) $P$ for two, sharing a scarce resource: soil phosphorus acquisition in the rhizosphere of intercropped species. Plant physiology 156: 1078-1086.

14. Zogli P, Pingault L, Libault M (2017) Physiological and molecular mechanisms and adaptations strategies in soybean (Glycine max) under phosphate deficiency. In: Legume Nitrogen Fixation in Soils with Low Phosphorus Availability: Adaptation and Regulatory Implication pp. 219-242.

15. Bargaz A, Zaman-Allah M, Farissi M, Lazali M, Drevon JJ, et al. (2015) Physiological and molecular aspects of tolerance to environmental constraints in grain and forage legumes. Int J Mol Sci 16(8): 1897619008.

16. Makoi JHJR, Ndakidemi PA (2007) Biological, ecological and agronomic significance of plant phenolic compounds in rhizosphere of the symbiotic legumes. African Journal of Biotechnology 6(12): 1358-1368.

17. M'sehli W, Dell'Orto M, Donnini Silvia, De Nizi P, Zocchi G, et al. (2009) Variability of metabolic responses and antioxidant defence in two lines of Medicago ciliaris to Fe deficiency. Plant Soil 320(1): 219-230.
18. Su Y, Zhang Z, Su G, Liu J, Liu C, et al. (2012) Genotypic differences in spectral and photosynthetic response of peanut to iron deficiency. Journal of Plant Nutrition 38(1): 145-160.

19. M'sehli W, Jelali N, Dell'Orto M, Abdelly C, Zocchi G, et al. (2011) Responses of two lines of Medicago ciliaris to Fe deficiency under saline conditions. Plant Growth Regulation 64 (3): 221-230.

20. Kallala N, M'sehli W, Jellali N, Batnini M, Badri M, et al. (2019) Biodiversity within Medicago truncatula genotypes toward response to iron deficiency: Investigation of main tolerance mechanisms. Plant Species Biology 34(3): 95-109.

21. M'sehli BouftiraW, Jelali N, Zorrig W, Rabhi M, Abdelly C, et al. (2012) Responses of two forage legumes to direct iron deficiency: a comparative study. Journal of Biological Research-Thessaloniki 18.

22. Pii Y, Mimmo T, Tomasi N, Terzano R, Cesco S, et al. (2015) Microbial interactions in the rhizosphere : beneficial influences of plant growthpromoting rhizobacteria on nutrient acquisition process. A review. Biol Ferti Soils 51(4): 403-415.

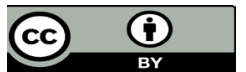

This work is licensed under Creative Commons Attribution 4.0 License

To Submit Your Article Click Here: Submit Article

DOI: 10.32474/CIACR.2020.08.000291

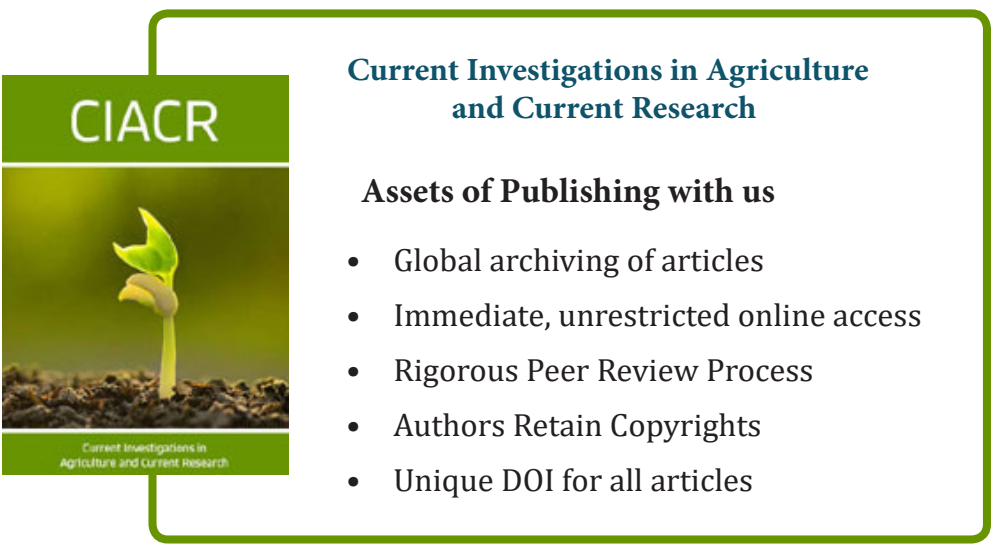

